ScIDice

\section{Comparison and Evaluation of different Antibiotics prescribed to Elderly Patients Post Extraction}

Kirtana Gopalasamy ${ }^{1}$, Hemavathy O.R ${ }^{2 *}$, Pradeep $\mathrm{D}^{3}$

${ }^{1}$ Saveetha Dental College and Hospitals, Saveetha Institute of Medical and Technical Sciences Saveetha University, Chennai-600077, Tamilnadu, India.

${ }^{2}$ Associate Professor, Department of Oral and Maxillofacial Surgery, Saveetha Dental College And Hospitals, Saveetha Institute Of Medical And Technical Sciences, Saveetha University, Chennai-600077, Tamilnadu, India.

${ }^{3}$ Associate Professor, Department of Oral and Maxillofacial Surgery, Saveetha Dental College and Hospitals, Saveetha Institute of Medical and Technical Sciences Saveetha University, Chennai-600077, Tamilnadu, India.

\title{
Abstract
}

Antibiotics are not an alternative to dental intervention, they are an adjunct. Judicious use of antibiotics in conjugation with surgical therapy is the most appropriate method to treat Odontogenic infections. Antibiotic prescribing practices among general dentists and dental specialists among elderly patients remains poorly understood. Aim of the study was to compare and evaluate the various antibiotics prescribed to elderly patients post extraction. The patients records were reviewed and the data of patients who visited between June 2019 to March 2020 were analyzed. 4471 patients above the age of 40 years who underwent extractions were evaluated for the antibiotic prescribed post extraction and were included in the study. Retrospective analysis was done based on the collected data. Statistical analysis was performed in SPSS Software, data was analysed by descriptive and inferential statistics. Amoxicillin was the most commonly prescribed antibiotic post extraction (87.01\%) and metronidazole was the second highest prescribed antibiotic post extraction $(6.78 \%)$. Amoxicillin of dosage $(500 \mathrm{mg})$ was the most commonly administered antibiotic in the age group 40-65 years, Pearson Chi Square value- 434a ,p value- 0.933 (statistically insignificant). From the present study we were able to conclude that Amoxicillin was the most commonly prescribed primary antibiotic among all the age groups. This was followed by Metronidazole and amoxicillin combinations with clavulanic acid and metronidazole. Age and gender did not influence the choice of antibiotic prescribed post extraction.

Keywords: Amoxicillin; Antibiotics; Elderly Patients; Post Extraction Prescription.

\section{Introduction}

The incidence of oral diseases increases with the age in the elderly. Oral health is very important for elderly patients who are more at risk for oral diseases, age related diseases, chronic diseases and many may require Multi drug regimen and treatment for cure [25]. In recent years the elderly are paying more attention towards their oral health care. Oral surgery especially tooth extraction is also increasingly common in recent years and proper antibiotic regimen must be followed pre and post extractions to make sure there is any hassle free, complication free procedure to minimise the risk as much as possible $[17,22,1]$. From studies conducted it was seen that General dental practitioners in Europe extract up to seven teeth per week .with the highest tooth extractions being more commonly done in elderly patients in the sixth and seventh decade. [8], The main reason for extraction being more commonly carried out in elderly patients is due to grossly decayed teeth and in. It's a case of periodontally compromised teeth $[38,37]$. In other studies it was seen that Elderly patients are prescribed the highest proportion of medications. Health Pharmacotherapy is the last important intervention for care in elderly patients.

The Aging process included 3 types of physiological changes that are seen, changes in cellular homeostatic mechanisms, which may include regulation of body temperature, as well as blood and extracellular fluid volumes; those related to a decrease in organ mass; and those involving a decline in, and loss of, the functional reserves of the body's systems [29].

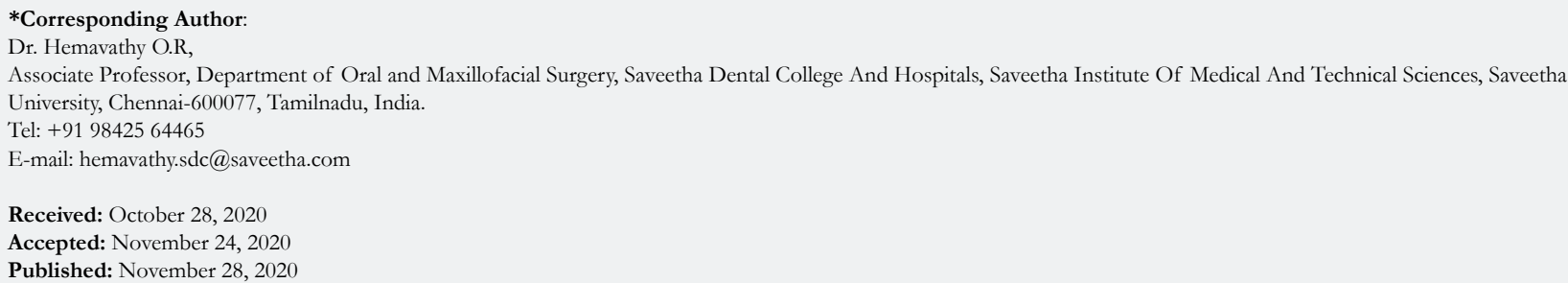

Citation: Kirtana Gopalasamy, Hemavathy O.R, Pradeep D. Comparison and Evaluation of different Antibiotics prescribed to Elderly Patients Post Extraction Int J Dentistry Oral Sci. 2020;S5:02:0019:107-111. doi: http://dx.doi.org/10.19070/2377-8075-SI02-050019

Copyright: Hemavathy O.R $^{\circ} 2020$. This is an open-access article distributed under the terms of the Creative Commons Attribution License, which permits unrestricted use, distribution and reproduction in any medium, provided the original author and source are credited. 
The following are the most common Changes most often encountered in the elderly:

\section{Pharmacokinetics of a drug}

This is mainly used to describe the disposition of a drug after its administration, specifically, its absorption, distribution, biotransformation and elimination. Alterations in these functions in the elderly may often lead to age-related decline in physiological functions, such as decreased cardiac output, decreased renal function or decreased plasma albumin concentrations [9]. As the patient ages the Biotransformation and Elimination of the drug is affected. Slower metabolism decreases and this may lead to accumulation of medication in plasma, this increasing the concentration and toxicity, as in elderly the GFR is also reduced also leading to toxicity form the drug.

The overall impact of these pharmacokinetic changes in the elderly is to increase the duration of a drug's action and its plasma concentration, with the latter leading to increased potency.

\section{Pharmacodynamics of a drug}

Pharmacodynamics refers to the action of a drug on the body, which may be affected by physiological changes in organ function related to aging or specific disease processes.As the body ages, the affinity of some medications for particular receptor sites may change [39]. For instance we might be able to see in many elderly patients they show exaggerated responses to CNS drugs [5]. This is partly a result of an underlying age-related decline in CNS function and partly a result of increased sensitivity to certain benzodiazepines, general anesthetics and opioids [28].

For elderly patients, prescribed medications often require modifications in size and frequency of dose and duration of the prescription. Here, we discuss the prescription medications commonly used in daily dental practice - local anesthetics, analgesics and antibiotics - and modifications needed when prescribing for the elderly.

No significant modifications of pharmacotherapy of antibiotics are needed in a healthy elderly patient. Beta Lactam antibiotics which include the penicillins, are the most commonly used antibiotics in dental practice. Penicillins have not been shown to cause differential side effects or problems in older people compared with younger adults. Nonetheless, because renal excretion of penicillins and cephalosporins decreases with the physiological aging of the kidneys, dose reduction is advisable in elderly patients with renal disease.

Older patients are more susceptible to adverse drug reactions and drug interactions. Polypharmacy is a continuing problem in the elderly and only seems to be getting worse as the elderly population grows along with the number of drugs approved [11]. Because elderly patients generally have several co-morbidities and are on several medications, there may also be little information regarding drug-drug or drug-disease interactions $[39,11]$.

Dental clinics have shown about $10 \%$ of overall antibiotic prescription $[35,10]$. Antibiotics are prescribed for various reasons in the dental clinics to treat local and systemic problems. Among various invasive procedures, the rate of antibiotic prescription is particularly high after tooth extractions. The high rate of broadspectrum antibiotic prescription in dental clinics has been identified as a cause of antibiotic resistance [13]. In order to prevent antibiotic-resistance development caused by the misuse of antibiotics, broad-spectrum antibiotic use should be limited to cases of severe infection [14]. Recently, misuse of antibiotics has been highlighted as the main reason for increased antibiotic-resistance $[12,30]$. The usage of Broad spectrum antibiotics must be minimised as much as possible and must only be used in severe cases.

Previously our team had conducted numerous clinical trials [20, $31,33]$ and lab animal studies $[23,19,21,36,2]$ and in intro studies $[7,34,27,3,15]$ over the past 5 years. Now we are focusing on epidemiological surveys. The idea for the current research stemmed from the current interest in our public.

Because of the ongoing state of controversy and consequences of the best antibiotic of choice to be prescribed for elderly patients undergoing extractions. Our department is passionate about research we have published numerous high quality articles in this domain over the past years ( (Kavitha et al. 2014), (Praveen et al. 2001),(Devi and Gnanavel 2014), (Putchala et al. 2013), (Vijayakumar et al. 2010), (Lekha et al. 2014b, [a] 2014) (Danda 2010) (Danda 2010) (Parthasarathy et al. 2016) (Gopalakannan, Senthilvelan, and Ranganathan 2012), (Rajendran et al. 2019), (Govindaraju, Neelakantan, and Gutmann 2017), (P. Neelakantan et al. 2015), (PradeepKumar et al. 2016), (Sajan et al. 2011), (Lekha et al. 2014b), (Prasanna Neelakantan, Grotra, and Sharma 2013), (Patil et al. 2017), (Jeevanandan and Govindaraju 2018), (Abdul Wahab et al. 2017), (Eapen, Baig, and Avinash 2017), (Menon et al. 2018), (Wahab et al. 2018), (Vishnu Prasad et al. 2018), (Uthrakumar et al. 2010), (Ashok, Ajith, and Sivanesan 2017), (Prasanna Neelakantan et al. 2015). This study aims to compare and evaluate the different antibiotics prescribed to elderly patients post extraction.

\section{Materials And Methods}

\section{Study Setting}

The study was conducted with the approval of the Institutional Ethics Committee [SDC/SIHEC/2020/DIASDATA/0619-0320]. The study consisted of one reviewer, one assessor and one guide .

\section{Study Design}

The study was designed to include all dental patients above 40 years undergoing extraction. The patients who did not fall into this inclusion criteria were excluded.

\section{Sampling Technique}

The study was based on a non probability consecutive sampling method. To minimise sampling bias, all case sheets of patients who underwent treatment in their mandibular third molar were reviewed and included.

\section{Data Collection and Tabulation}

Data Collection was done using the patient database with the timeframe work 01 June 2019 and 31 march 2020. About 42,000 
case sheets were reviewed and those fitting under the inclusion criteria were included. Cross verification was done with the help of Photographs and radiographic evidence. To minimise sampling bias all data were included. The exclusion criteria was patients with systemic illness. Data was downloaded from DIAS and imported to Excel, Tabulation was done. The values were tabulated and analysed.

\section{Statistical Analysis}

Descriptive statistics were performed using SPSS by IBM on the tabulated values. Chi-Square test was performed and the $\mathrm{p}$ value was determined to evaluate the significance of the variables it was used to evaluate the association between the age and gender with the type of treatment done in the third molar. The results were obtained in the form of graphs and tables.

\section{Results And Discussion}

From the present study we were able to see that out of $4471 \mathrm{pa}-$ tients, many different antibiotics were prescribed based on the patient's age and underlying medical conditions of the patient. Out of these patients about 3890 patients were prescribed amoxicillin post extraction while the other two highest prescribed antibiotics work metronidazole With 303 patients prescribed with the same And other combinations of antibiotics word amoxicillin which clavulanic acid in about 120 patients and amoxicillin with metronidazole in 115 patients.

Other lesser frequently used antibiotics for elderly patients were Novomox in (21 patients) and Cefixime in (6 patients).
Based on the age we were able to see that amoxicillin was the highest and the most prescribed antibiotic post extraction in both the age groups, while the other frequently used drugs were amoxicillin with clavulanic acid and Amoxicillin with Metronidazole Was seen to be given most in the age group 40 to 60 years. Amoxicillin and metronidazole Were the highest prescribed drugs in the age group 66 to 92 years.

Antibiotics are commonly prescribed in dental clinics along with NSAIDs. Antibiotics are frequently prescribed to prevent local and systemic infections that may occur after any surgical treatment [18].

In a previous study performed by a German researcher, amoxicillin was the most frequently prescribed antibiotic but broad spectrum antibiotics such as amoxicillin clavulanate or Clindamycin were frequently used as prescription post extraction in many dental clinics. It was seen that Clindamycin was the second highest prescribed antibiotic in the German study [13] with about 34.9\% and in American studies [10] it was seen to be at $15.64 \%$ In other previous studies conducted it was seen that most common antibiotic prescribed post extraction were Penicillin (43\%), followed by penicillin with beta lactam inhibitor 18.76 percentage and metronidazole. Metronidazole was seen to be the third highest prescribed antibiotic in the Korean studies [6] with about $12.29 \%$ which was very much Similar to our study also when compared with a few studies done in Germany, America and South Africa it was seen to be less than $1 \%$. With this we were able to see that most of the results coincided with other research conducted by dentists in South Africa [24], Germany, Korea, United States. In these studies it was noted that the study conducted in South Africa

Figure 1. Bar graph represents the frequency distribution of various antibiotics prescribed post extraction in elderly patients.Y axis represents the percentage of patients undergoing extraction and $\mathrm{X}$ Axis represents the antibiotics prescribed post extraction. From this graph we see that amoxicillin was the most widely prescribed antibiotic post extraction (87.01\%) and metronidazole was the second highest prescribed antibiotic post extraction $(6.78 \%)$.

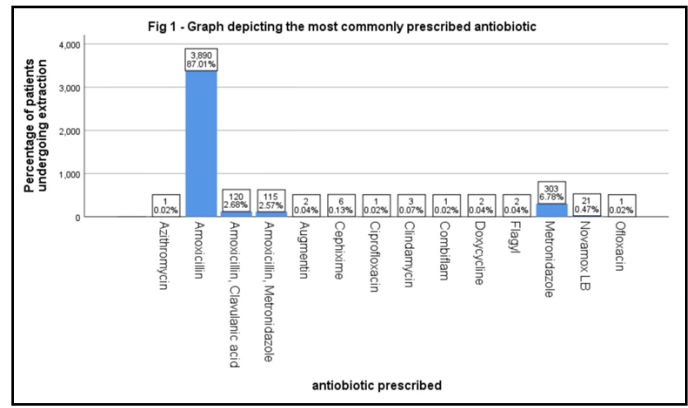

Figure 2. Bar graph represents the association between the age and the most commonly prescribed antibiotics to the patient. $\mathrm{X}$ axis represents the age distribution in years. $\mathrm{Y}$ axis represents the total number of patients undergoing extraction. From this graph we see that amoxicillin of dosage $(500 \mathrm{mg})$ was the most commonly administered antibiotic in the age group 40-65 years. Chi-square test, Pearson Chi Square value- $.434, p$ value- 0.93 ( $p>0.05$ which is statistically not significant.

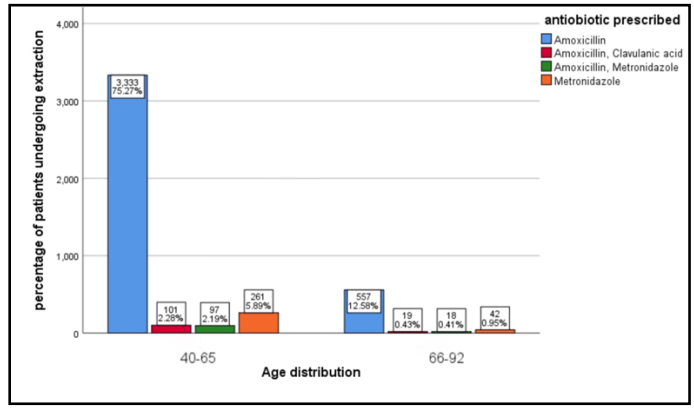


Figure 3. Bar graph represents the association between the age and the least commonly prescribed antibiotics to the patient. $\mathrm{X}$ axis represents the age distribution in years. $\mathrm{Y}$ axis represents the total number of patients undergoing extraction. From this graph we see that Novam ox LB was prescribed the most in the age group of 40-65 years it was one of the lesser prescribed antibiotics used. Chi-square test, Pearson Chi-square value- 5.873 , p value- 0.753 (p value $>0.05$ statistically not significant).

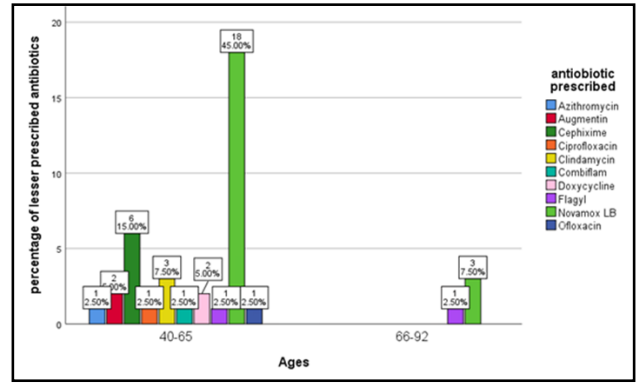

reported that Penicillin prescription was about $80.9 \%$ which was markedly high when compared to our study. And the results from the German studies showed that it was $51.4 \%$ and the American study was $68 \%$ which was similar to the Korean study and was similar to our study.

In most of the studies conducted in Korea, South Africa, Germany, America penicillins was the primary antibiotic prescribed post extractions in patients of all age groups the use of antibiotics is markedly variable across countries. Those differences are likely due to difference in educations help policies demographics and clinical experiences also it may be due to difference of opinion and clinical expertise of various dentists.In the study conducted we were able to see that the rate of antibiotic prescription after any extraction was about $90 \%$, this was seen to be high when compared to studies conducted in Korea $(81.85 \%)$, Australia (75\%) [16], South Africa (54.5\%), Belgium (25\%) [26].

Furthermore, the more invasive tooth extraction procedures and techniques resulted in a greater frequency of prescription of broad spectrum antibiotics post extraction that is penicillin with beta lactam ACE inhibitor, second to 4th generation Cephalosporin these results were also in agreement with previous studies conducted. Patients in older age groups that are 65 years and above only simple penicillin antibiotic prescriptions word given this can be attributed to simple extractions due to parental diseases being more common in older age groups resulting in mobile teeth and here by giving easier extractions. While in the age group 42-65 years amoxicillin and beta lactam inhibitors were used. Most of the older population in adults needs lower doses of medications than others due to the fact that older patients have a predisposing factor to a large number of co-morbidities and take many medications. In a study conducted by James N Wooten [39], it was seen that $40 \%$ of adults aged 65 years and older are on 5 or above daily medications . Leading to adverse drug reactions in many. Polypharmacy is coming about using problems in the adult population. It was seen a few studies conducted in the United States there were utilization of tools like the Beers Criteria or the STOPP (Screening Tool of Older Persons' potentially inappropriate Prescriptions) and START (Screening Tool to Alert doctors to Right Treatment) guidelines which identify potentially high risk, dangerous drugs in elderly patients is also quite useful [32, 4].

Inappropriate use of medications has nearly become an epidemic in the elderly population and the only way to with the help of improving how medications are utilised and judicial prescription of antibiotics and drugs in the elderly. As the elderly population is more prone to and vulnerable to drug related issues and cause harm. Practitioners and dentists must be careful and keep in mind the patient's condition and history before prescribing Drugs and must follow strict rules to promote safe pharmacotherapy.

\section{Conclusion}

Within the limits of the study it can be concluded antibiotics are commonly prescribed after tooth extraction in elderly patients to avoid any postoperative complications. Penicillins such as Amoxicillin were the most commonly prescribed primary antibiotic among all the age groups. This was followed by metronidazole, amoxicillin combinations with clavulanic acid and metronidazole.

\section{Acknowledgement}

I would like to thank Saveetha Dental College for the constant encouragement with my work during all stages.

\section{References}

[1]. Post-White House Conference on Aging Reports, 1973. No. 5270-01994 Washington, D.C.: U.S. Government Printing Office, 1973. 859 pp. \$5.20 (1974) Social Work. doi: 10.1093/sw/19.4.504-a.

[2]. Abhinav RP, Selvarasu K, Maheswari GU, Taltia AA. The patterns and etiology of maxillofacial trauma in South India. Ann. Maxillofac. Surg. 2019 Jan;9(1):114.

[3]. Sweta VR, Abhinav RP, Ramesh A. Role of Virtual Reality in Pain Perception of Patients Following the Administration of Local Anesthesia. Ann Maxillofac Surg. 2019 Jan-Jun;9(1):110-113.Pubmed PMID: 31293937.

[4]. Barry PJ, Gallagher P, Ryan C, O'mahony D. START (screening tool to alert doctors to the right treatment)-an evidence-based screening tool to detect prescribing omissions in elderly patients. Age and ageing. $2007 \mathrm{Nov}$ 1;36(6):632-8

[5]. Bowie MW, Slattum PW. Pharmacodynamics in older adults: a review. Am J Geriatr Pharmacother. 2007 Sep 1;5(3):263-303.

[6]. Choi YY. Prescription of antibiotics after tooth extraction in adults: a nationwide study in Korea. J Korean Assoc Oral Maxillofac Surg. 2020 Feb;46(1):49-57.Pubmed PMID: 32158681.

[7]. Christabel A, Anantanarayanan P, Subash P, Soh CL, Ramanathan M, Muthusekhar MR, et al. Comparison of pterygomaxillary dysjunction with tuberosity separation in isolated Le Fort I osteotomies: a prospective, multi-centre, triple-blind, randomized controlled trial. Int J Oral Maxillofac Surg. 2016 Feb;45(2):180-5.Pubmed PMID: 26338075.

[8]. Chrysanthakopoulos NA. Reasons for extraction of permanent teeth in Greece: a five-year follow-up study. Int Dent J. 2011 Feb;61(1):19-24.Pubmed PMID: 21382029.

[9]. Corsonello A, Onder G, Maggio M, Corica F, Lattanzio F. Medications affecting functional status in older persons. Curr. Pharm. Des. 2014 May 1;20(19):3256-63. 
[10]. Durkin MJ, Hsueh K, Sallah YH, Feng Q, Jafarzadeh SR, Munshi KD, et al. An evaluation of dental antibiotic prescribing practices in the United States. J Am Dent Assoc. 2017 Dec 1;148(12):878-86.

[11]. Fatehi M, Haroni HA, Morshedy AH. Designing infill directional drilling in mineral exploration by using particle swarm optimization algorithm. Arab. J. Geosci. 2017 Nov 1;10(22):487.

[12]. Garg AK, Agrawal N, Tewari RK, Kumar A, Chandra A. Antibiotic prescription pattern among Indian oral healthcare providers: a cross-sectional survey. J Antimicrob Chemother. 2014 Feb 1;69(2):526-8.

[13]. Halling F, Neff A, Heymann P, Ziebart T. Trends in antibiotic prescribing by dental practitioners in Germany. J Craniomaxillofac Surg. 2017 Nov 1;45(11):1854-9.

[14]. Holen $\varnothing$, Alberg T, Blix HS, Smith I, Neteland MI, Eriksen HM. Broadspectrum antibiotics in Norwegian hospitals. Tidsskr Nor Laegeforen. 2017 Mar 7;137(5):362-366.Pubmed PMID: 28272566.

[15]. Vijayakumar Jain S, Muthusekhar MR, Baig MF, Senthilnathan P, Loganathan S, Abdul Wahab PU, et al. Evaluation of Three-Dimensional Changes in Pharyngeal Airway Following Isolated Lefort One Osteotomy for the Correction of Vertical Maxillary Excess: A Prospective Study. J Maxillofac Oral Surg. 2019 Mar;18(1):139-146.Pubmed PMID: 30728705.

[16]. Jaunay T, Dambrook P, Goss A. Antibiotic prescribing practices by South Australian general dental practitioners. Aust. Dent. J. 2000 Sep;45(3):17986.

[17]. Jesudasan JS, Wahab PU, Sekhar MR. Effectiveness of $0.2 \%$ chlorhexidine gel and a eugenol-based paste on postoperative alveolar osteitis in patients having third molars extracted: a randomised controlled clinical trial. $\mathrm{Br} \mathrm{J}$ Oral Maxillofac Surg. 2015 Nov;53(9):826-30.Pubmed PMID: 26188932.

[18]. de Kraker ME, Stewardson AJ, Harbarth S. Will 10 Million People Die a Year due to Antimicrobial Resistance by 2050? PLoS Med. 2016 Nov 29;13(11):e1002184.Pubmed PMID: 27898664.

[19]. Kumar S. Knowledge, attitude and awareness of dental undergraduate students regarding HIV/AIDS patients “. Asian J. Pharm. Clin. Res. 2017:175.

[20]. Kumar S. Relationship between dental anxiety and pain experience during dental extractions. Asian J. Pharm. Clin. Res. 2017;10(3):458.

[21]. Kumar S. The emerging role of botulinum toxin in the treatment of orofacial disorders: Literature update. Asian J. Pharm. Clin. Res. 2017;10(9):21-9.

[22]. Kumar S, Rahman RE. Knowledge, awareness, and practices regarding biomedical waste management among undergraduate dental students. Asian J. Pharm. Clin. Res. 2017;10(8):341.

[23]. Kumar, S. and Sneha, S. (2016) 'KNOWLEDGE AND AWARENESS REGARDING ANTIBIOTIC PROPHYLAXIS FOR INFECTIVE ENDOCARDITIS AMONG UNDERGRADUATE DENTAL STUDENTS', Asian Journal of Pharmaceutical and Clinical Research, p. 154. doi: 10.22159/ajpcr.2016.v9s2.13405

[24]. Lalloo R, Solanki G, Ramphoma K, Myburgh NG. Antibiotic-prescribing patterns of South African dental practitioners following tooth extractions. J
Investig Clin Dent. 2017 Nov;8(4).Pubmed PMID: 27778471.

[25]. Lodi G, Figini L, Sardella A, Carrassi A, Del Fabbro M, Furness S. Antibiotics to prevent complications following tooth extractions. Cochrane Database Syst. Rev. 2012(11).

[26]. Mainjot A, D'Hoore W, Vanheusden A, Van Nieuwenhuysen JP. Antibiotic prescribing in dental practice in Belgium. Int. Endod. J. 2009 Dec;42(12):1112-7.

[27]. Marimuthu M, Andiappan M, Wahab A, Muthusekhar MR, Balakrishnan A, Shanmugam S. Canonical Wnt pathway gene expression and their clinical correlation in oral squamous cell carcinoma. Indian J Dent Res. 2018 May $1 ; 29(3): 291$

[28]. Midlv, P. (2013) 'Pharmacokinetics and pharmacodynamics in the elderly', OA Elderly Medicine. doi: 10.13172/2054-734x-1-1-621.

[29]. Nigam Y, Knight J, Bhattacharya S, Bayer A. Physiological changes associated with aging and immobility. J. Aging Res.2012.1-2.

[30]. Oberoi SS, Dhingra C, Sharma G, Sardana D. Antibiotics in dental practice: how justified are we. Int. Dent. J. 2015 Feb 1;65(1):4-10.

[31]. Packiri S, Gurunathan D, Selvarasu K. Management of paediatric oral ranula: a systematic review. J Clin Diagn Res. 2017 Sep;11(9):ZE06.

[32]. 2019 American Geriatrics Society Beers Criteria ${ }^{\circ}$ Update Expert Panel, Fick DM, Semla TP, Steinman M, Beizer J, Brandt N, Dombrowski R, et al. American Geriatrics Society 2019 updated AGS Beers Criteria ${ }^{\circledR}$ for potentially inappropriate medication use in older adults. J. Am. Geriatr. Soc. 2019 Apr;67(4):674-94

[33]. Patil SB, Durairaj D, Suresh Kumar G, Karthikeyan D, Pradeep D. Comparison of Extended Nasolabial Flap Versus Buccal Fat Pad Graft in the Surgical Management of Oral Submucous Fibrosis: A Prospective Pilot Study. J Maxillofac Oral Surg. 2017 Sep;16(3):312-321.Pubmed PMID: 28717289.

[34]. Patturaja K, Pradeep D. Awareness of Basic Dental Procedure among General Population. Research J. Pharm. and Tech. 2016 Sep 1;9(9):1349.

[35]. Pipalova R, Vlcek J, Slezak R. The trends in antibiotic use by general dental practitioners in the Czech Republic (2006-2012). Int Dent J. 2014 Jun;64(3):138-43.Pubmed PMID: 24410046.

[36]. Rao TD, Kumar MS. Analgesic efficacy of paracetamol vs ketorolac after dental extractions. Research J. Pharm. and Tech. 2018 Aug 1;11(8):3375-9.

[37]. Sleeman D, Barry H, Ryan C, Allen F. Day case oral surgery: a review of 25 years experience at the Dublin Dental Hospital. Br. Dent. J. 1995 Sep;179(6):221-4

[38]. Thomas D, Walker R, Smith A, Shepherd J. The provision of oral surgery services in England and Wales 1984-1991. Br. Dent. J. 1994 Mar;176(6):2159.

[39]. Wooten JM. Pharmacotherapy considerations in elderly adults. South Med J. 2012 Aug 1;105(8):437-45. 